\title{
Combating Corrosion in Transmission Pipelines in Marine Environment Using Vernomia Amydalina as Inhibitor
}

\author{
Samson Nitonye ${ }^{1}$, Umoh Ofonime Emmanuel ${ }^{2}$, A. Ogbonnaya Ezenwa ${ }^{2}$ \\ ${ }^{1}$ Department of Marine Engineering, Rivers State University, Port Harcourt, Rivers State, Nigeria \\ ${ }^{2}$ Department of Mechanical/Marine Engineering, Niger Delta University, Amassoma, Bayelsa State, Nigeria \\ Email: nitonye.samson@ust.edu.ng
}

How to cite this paper: Nitonye, S., Emmanuel, U.O. and Ezenwa, A.O. (2018) Combating Corrosion in Transmission Pipelines in Marine Environment Using Vernomia Amydalina as Inhibitor. Open Journal of Marine Science, 8, 450-472. https://doi.org/10.4236/ojms.2018.84025

Received: August 22, 2018

Accepted: October 23, 2018

Published: October 26, 2018

Copyright $\odot 2018$ by authors and Scientific Research Publishing Inc. This work is licensed under the Creative Commons Attribution International License (CC BY 4.0). http://creativecommons.org/licenses/by/4.0/

\section{Open Access}

\begin{abstract}
Pipelines are system of pipes designed to transport liquids, gases or solid/liquid mixtures over long distances. Some are used for domestic, household and sewage purposes. Others are buried underground or submerged in water for transportation of natural oil and gas $(O \& G)$ products. In this work, the specimens had to be kept in a workable state and steps were taken to prepare each specimen: all cuts and sheared edges were ground out to prevent them from becoming sites for preferential attack. The finishing of the specimen surface with grit abrasive paper (sand paper) and rinsing of the specimens in distilled water were done. Then degreasing of specimen in acetone and air-dried were carried out. Upon drying, the specimens were immediately weighed to obtain their initial weights. Twelve specimens were used for the test as follows: 6 Aluminum (Al); and 6 mild steel (MS) samples. With a $2 \mathrm{M}$ concentration of Vernomia Amydalina (VA) extract solution, the MS and $\mathrm{Al}$ samples were immersed in different plastic containers containing 400 $\mathrm{ml}$ of seawater with $\mathrm{pH}$ value of 7.25 with no (0\%) inhibitor added to it. A $5 \%$ $(400 \mathrm{ml})$ of the VA solution was poured into the measuring cylinder for each sample-Al and MS. The specimens were suspended by the strings and completely immersed in the different percentage test media. The same procedure was carried out for each of the different percentages, $10 \%, 15 \%, 20 \%$, and $25 \%$ and a total of 12 solutions were set up. The experimental procedure used was that seawater of $7.25 \mathrm{pH}$ was obtained from Abonnema water front of Rivers State. At the end of every week (168 hours), the specimens were removed from the corrosive media. Observation and recording of appearance of the specimen noting sites were done. Cleanings of specimen with white handkerchief or tissue paper were carried out and washing of specimen with distilled water, scrubbing of specimen with a soft brush and dipping the spe-
\end{abstract}


cimen into acetone after washing, it was removed to air-dry and weighed. It is observed that optimum inhibition of coupons was obtained between 15\% $25 \%$ of VA solution during the first four weeks of testing. At the fifth week the inhibitor was gradually losing its effectiveness. This means that more inhibitor need be added at regular intervals to sustain the effectiveness of the inhibitor.

\section{Keywords}

Pipelines, Corrosion, Environment, Sea Water, Inhibitors, Specimen, VA Solution, Corrosion Rate (CR), Weight Loss (WL)

\section{Introduction}

Pipelines are system of pipes designed to transport liquids, gases or solid/liquid mixtures over long distances. More often we tend to limit the functions of these pipelines to our domestic, household and sewage use only. We are not often aware of the large number of pipelines that are continually in service as a primary means of transportation across, nations and continent mainly because they are buried underground over decades and their presence is rarely obvious except at valves, pumping stations and terminals. Large transmission pipelines however are buried underground or submerged in water for transportation of natural $\mathrm{O}$ $\& \mathrm{G}$ products from drillings to refineries and filling station.

The history of transmission pipelines dates far back as 400BC about 2500 years ago. Its first users were the Chinese, bamboo pipeline was used to transport natural gas which was used to light its capital city Peking. In America, J. D. Rockefeller saw the need for the use of pipelines when railroad transporters gave him an ultimatum to pay huge sum of money for his petroleum products to be conveyed from the refineries to their selling point with this development he dwindled their efforts and became a very powerful man in America [1]. Till date transmission pipelines are the most economical and efficient means of bulk fluid transportation due to its flexibility of route as compared to rail, truck and train transportation. These pipelines are designed to operate over decades unnoticed and without failure, however, they are exposed to unfavorable conditions and they tend to react with the environment, thereby making them susceptible to corrosion [2]. Due to the capital cost of pipelines, their inaccessibility when buried, the disruption to supplies during renewal and the potentially catastrophic consequences of undetected corrosion failure, Phil Hopkins stressed the need to ensure safety of pipelines during operation since it was the major means of supplying energy required for daily consumption [3]. It is of vital importance that these pipelines do not corrode because accompanied with pipeline failure are potential explosion, human and economic risk and environmental disaster [4].

Corrosion reduces the structural integrity of pipeline, makes it deteriorate and over spill its content into the environment thereby rendering it an unsafe chan- 
nel for transporting toxic and hazardous fluids. This work is aimed at combating corrosion in transmission pipeline using VA solution as inhibitor. It will analyze the various forms of corrosion; describe the basic principles of corrosion of mild steel and Al, identify the various conditions necessary for corrosion occurrence, determine the effect of inhibitor on corrosion reaction and determine the parameters used for measuring CR.

\section{Corrosion}

Corrosion is the deterioration and gradual destruction of the component of a material as a result of the chemical or electrochemical reactions of this material and its environment. A general definition of corrosion is the degradation of material through environmental interactions; this includes manmade and naturally occurring structures [5]. For the purpose of this work the main emphasis was on the corrosion of transmission steel and $\mathrm{Al}$ pipelines submerged in seawater of high salinity. These materials tend to corrode when exposed in aqueous environments which are either water or moist soil as the case may be. This environment acts as the electrolyte and corrosion occur as an electrochemical process. Corrosion can be classified as dry and wet corrosion, chemical and electrochemical corrosion. Most corrosion problems encountered fall into five basic categories: uniform or general corrosion [6], localized corrosion [7], metallurgical induced corrosion [8], mechanically assisted corrosion [9] and stress corrosion cracking [10]. These five basic types of corrosion can be broken down into eight visually identifiable forms. They include the general or uniform corrosion, galvanic corrosion, crevice corrosion and pitting corrosion. Others are inter granular corrosion, micro biologically influenced corrosion, erosion corrosion and stress cracking corrosion [11] [12].

Reactions in a typical galvanic cell are seen at the anode as $\mathrm{Fe} \rightarrow \mathrm{Fe}^{2+}+2 \mathrm{e}$ - and at the Cathode as $2 \mathrm{e}-+2 \mathrm{H}^{+} \rightarrow \mathrm{H}_{2}$. In the Electrolyte it is $\mathrm{H}_{2} \mathrm{O} \rightarrow \mathrm{OH}^{-}+\mathrm{H}+\mathrm{Fe}^{2+}+$ $2 \mathrm{OH}^{-} \rightarrow \mathrm{Fe}(\mathrm{OH})_{2}$. It is noteworthy that three conditions must exist for galvanic corrosion to occur. These include; electrochemically disparate metals must be present, the metals must be in electrical contact, and the metals must be open to an electrolyte.

\subsection{Factors That Enhance Corrosion}

Every naturally occurring material has the tendency of corroding whether it is in use or not, more especially metals. However for a material to corrode there are several factors that must be present. These include presence of an anode and a cathode, a metallic bond, a voltage potential between the anode and cathode and an electrolyte with the presence of oxygen. The basic corrosion cell has these four parts, all of which must exist for corrosion to occur. Figure 1 shows a typical corrosion cell.

Other factors that affect corrosion can be discussed under two major headings; nature of metal and Nature of exposed environment. 


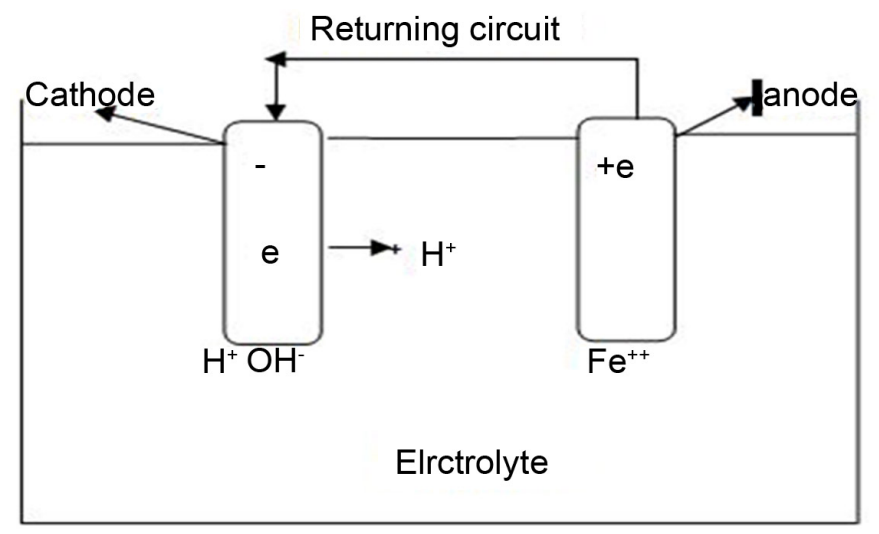

Figure 1. Basic Corrosion Cell [13].

\subsection{Nature of Metals}

1) Passivity of metal: A metal is said to be passive in a certain environment if it exhibits much lower CR than what is expected thermodynamically or from its position in the electrochemical series by forming a protective oxide layer which inhibits further corrosion. The metal oxide acts as a barrier by separating the metal surface from its environment and prevents corrosion until the reactants diffuse through the oxide film which take very long, or may never occur. Metals which exhibit passivity include iron, chromium, nickel, titanium and alloys of these metals. Passivation is associated with oxidizing environments. However, it is to be noted that a metal that is passive in one environment may not be passive in another environment. This is because passivity results from a continuing reaction between a metal and its environment. When a metal is passive, it is slow to corrode. Hence passivity offers an effective method of corrosion control [14].

2) Purity of the metal: the impurities present in metals form minute galvanic cells with the metal under approximate environment and the anodic part gets corroded. For instance the impurities such as $\mathrm{Pb}, \mathrm{Fe}$ or $\mathrm{C}$ present in zinc lead to the formation of tiny electrochemical cells at the exposed part of the impurity and corrosion of the zinc around the impurity takes place due to 'local action'. The rate of corrosion increases with the rate of exposure of the impurities. However, impurities which form solid solution in an alloy are homogeneous and hence do not form local action cells. Alloys having grains structure in which the electrode potentials of the crystals and the matrix are different may undergo appreciable corrosion. The dezincification in brass provides such example [15].

3) Oxidation potential: The extent of corrosion depends on the position of the metal in electrochemical and galvanic series. When two metals is in contact in the presence of an electrolyte the metal high up in the galvanic series become anodic and surfer corrosion. Furthermore, the more the two metals are apart in the galvanic series, the greater the difference in the oxidation potential and hence the faster are the corrosion of the anodic metal [16].

4) Over-voltage: If pure $\mathrm{Zinc}$ is placed in $1 \mathrm{M} \mathrm{H}_{2} \mathrm{SO}_{4}$ solution, it undergoes corrosion forming a film and generating bubbles of hydrogen gas on the im- 
mersed metal surface. Despite the high position of the metal as compared to hydrogen in the electrochemical series, the initial rate of reaction is very slow because of the high voltage (about $0.70 \mathrm{~V}$ ) which reduces the electrode potential or the driving force for the corrosion reaction to a small fraction of a volt. However, the corrosion of $\mathrm{Zinc}(\mathrm{Zn})$ can be accelerated by adding a drop of $\mathrm{CuSO}_{4}$ which reduces the high voltage to bring about an increase in the rate of corrosion [17].

5) Relative areas of the anode and cathode: When two steel plate of the same area are separately connected one to a copper plate (cathode) having the same and the other to a copper plate having a much more larger area, it can be observed that higher rate of corrosion is experienced at the anode connected to the larger area. It can therefore be stated that when anodic polarization is negligible, rate of corrosion directly proportional to the area of the cathode. Although the corrosion current is the same at both cathode and anode, the current density at the smaller anode will be much greater. The great demand for electron by the greater cathode area will have to be met by the smaller anode by forming more $\mathrm{Fe}^{2+}$ ions and hence the attack will be more severe [18].

\subsection{Nature of Environment of Exposure}

1) Temperature: $C R$ increases with increasing temperature because chemical reactions occur mostly at higher temperature [19].

2) $\mathrm{pH}$ value: $\mathrm{A}$ higher $\mathrm{pH}$ means there are fewer free hydrogen ions, and that a change of one $\mathrm{pH}$ unit reflects a tenfold change in the concentrations of the hydrogen ion. For example, there are 10 times as many hydrogen ions available at $\mathrm{pH} 7$ than at $\mathrm{pH}$. The $\mathrm{pH}$ scale commonly quoted ranges from 0 to 14 with a $\mathrm{pH}$ of 7 considered to be neutral. Substances with a pH less that 7 are considered to be acidic and substances with $\mathrm{pH}$ equal to or greater than 7 to be basic or alkaline. Thus, a pH of 2 is very acidic and a pH of 12 very alkaline. However, it is technically possible to have very acidic solutions with a $\mathrm{pH}$ lower than zero and concentrated caustic solutions with a $\mathrm{pH}$ greater than 14 . Such solutions are in fact typical of many ore extracting processes that require the digestive power of caustics and acids [20]. Low $\mathrm{pH}$ acid waters accelerate corrosion by supplying hydrogen ions to the corrosion process. Although even absolutely pure water contains some free hydrogen ions, dissolved carbon dioxide $\left(\mathrm{CO}_{2}\right)$ in the water can increase the hydrogen ion concentration.

3) Soil corrosivity: Corrosion of metals is an electrochemical process that results in the return of metals to their native state such as oxides and salts. The rate and magnitude of corrosion is a direct function of the environment in which the metal is placed. In the case of soil nails, the primary environment of interest is the soil. Soil is generally a three phase medium that consists of solid particles, liquids and gases, all of which can serve as electrolytes. An electrolyte is any substance containing free ions that behaves as an electrically conductive medium. In soils, for practical purposes, the liquid may be considered as water and the gas as 
air. Depending on the mineralogical composition of the solid particles in conjunction with the dissolved salts or pollutants in the water phase and the oxygen in the air phase, a variety of corrosive environments can develop in nature. For metals in soil and/or water, corrosion is typically a result of the contact of the metal with soluble salts. In general, the most corrosive soils contain relatively large concentrations of soluble salts in the form of sulfates and/or chlorides. There are many other factors that can contribute to corrosion including, but not limited to, the state of stress in the steel, metallurgy of steel, the texture and density of the soil, microbial activity, and stray currents [21] [22].

\subsection{Corrosion in Neutral or Alkaline Environment}

The corrosion of metals can also occur in fresh water, seawater, salt solutions, and alkaline or basic media. In almost all of these environments, corrosion occurs importantly only if dissolved oxygen is also present. Water solutions rapidly dissolve oxygen from the air, and this is the source of the oxygen required in the corrosion process. The most familiar corrosion of this type is the rusting of iron when exposed to a moist atmosphere [23].

$$
4 \mathrm{Fe}+6 \mathrm{H}_{2} \mathrm{O}+3 \mathrm{O}_{2} \rightarrow 4 \mathrm{Fe}(\mathrm{OH})_{3}
$$

In Equation (1), iron combines with water and oxygen to produce an insoluble reddish-brown corrosion product that falls out of the solution, this is depicted by the downward pointing arrow. During rusting in the atmosphere, there is an opportunity for drying, the ferric hydroxide dehydrates and forms the familiar red-brown ferric oxide (rust) or $\mathrm{Fe}_{2} \mathrm{O}_{3}$, as shown in Equation (2):

$$
2 \mathrm{Fe}(\mathrm{OH})_{3} \rightarrow \mathrm{Fe}_{2} \mathrm{O}_{3}+3 \mathrm{H}_{2} \mathrm{O}
$$

Similar reactions occur in Equation (3) and Equation (4) when zinc is exposed to water or moist air followed by natural drying.

$$
\begin{gathered}
2 \mathrm{Zn}+2 \mathrm{H}_{2} \mathrm{O}+\mathrm{O}_{2} \rightarrow \mathrm{Zn}(\mathrm{OH})_{2} \\
\mathrm{Zn}(\mathrm{OH})_{2} \rightarrow \mathrm{ZnO}+\mathrm{H}_{2} \mathrm{O}
\end{gathered}
$$

The resulting zinc oxide is the whitish deposit seen on galvanized pails, rain gutters, and imperfectly chrome-plated bathroom faucets. It also familiarly called "white rust" a non-protective and even destructive form of corrosion that attacks incompletely passivated galvanized steel material or galvanized components subjected to marine atmospheres.

\subsection{Methods of Combating Corrosion}

There are three major techniques of combating corrosion, namely: Material Selection, Environmental control, and Design features [20]. The use of corrosion inhibitors, these are chemical substances (additives) that can reduce the rate of corrosion. Inhibitors act to slow down the anodic or cathodic reaction by the formation of a protective film on the system confined in a corrosive environment to be protected. Secondly Anodic inhibitors; these include oxidizing agents like nitrates, molybdates and chromates. These anions react with metal ions 
formed at the anode during oxidation reaction to form sparingly soluble salts. These compounds are deposited at the anode sites forming protective films so that further preventing the anodic reactions. These inhibitors are found to be effective only when sufficient amount of inhibitors is added to the corrosion medium. So that entire anodic surface can be covered. Others are the cathodic inhibitor; these can act by inhibiting the cathodic reaction, which involves liberation of hydrogen or absorption of oxygen. They form a protective layer on the cathodic region so that evolution of hydrogen is retarded. Then the Green inhibitors; to replace the environmentally hazardous chromates, several non-chromates have been used as corrosion inhibitors. Extracts of plant materials top the list. The plant extracts are environmentally friendly, non-toxic and readily available. These extracts contain many ingredients. They contain several organic compounds which have polar atoms such as $\mathrm{O}, \mathrm{N}, \mathrm{P}$ and $\mathrm{S}$. They are adsorbed onto the metal surface through these polar atoms; protective films are formed. Adsorptions of these ingredients obey various adsorption isotherms the inhibition efficiency of plant. Extracts have been evaluated at room temperature [24].

\subsection{Limitations and Disadvantages of Corrosion Inhibitors}

Corrosion inhibitors have the following limitations and disadvantages: they contaminate the environment; most inhibitors are toxic in nature, they can only be used in closed systems and medium with zero flow rates and inhibitors lose their efficiencies with increasing concentration and temperature.

\section{Research Materials and Methods}

The laboratory test conducted is expected to provide data and facts for the appropriate material selection for use in pipelines installation on offshore structures salt water (seawater) environments, corrosion control and study of corrosion mechanisms. The standard employed is the ASTM G13: standard recommended practice for laboratory immersion corrosion testing of materials. This recommended practice which is based upon NACE standard TM-10-69, "test method laboratory corrosion testing of metals for the process industries" clearly describes the experimental procedure to be used [25].

The test apparatus include the corrosion testing specimens \#12; corrosive medium-seawater, $2 \mathrm{M}$ concentration of VA (bitter leaf) extract solution, distilled water, plastic bowl, top-loading electronic chemical weighing balance, measuring cylinder, beakers, rubber threads, acetone, wooden sticks. While the test specimens are MS and $\mathrm{Al}$ sheets were used as the corrosion testing specimens. They were obtained from a fabrication store. The shape and size of specimen; the specimen was machined to have a large surface area to mass ratio and a small ratio of edge area to total area was used. A square specimen of dimension $35 \times 30 \times$ $1 \mathrm{~mm}$ shown in Figure 2 was used. A $2.5 \mathrm{~mm}$ hole was bored near the top centre of the specimens. Total surface area of each specimen is given by the relation in Equation (5): 


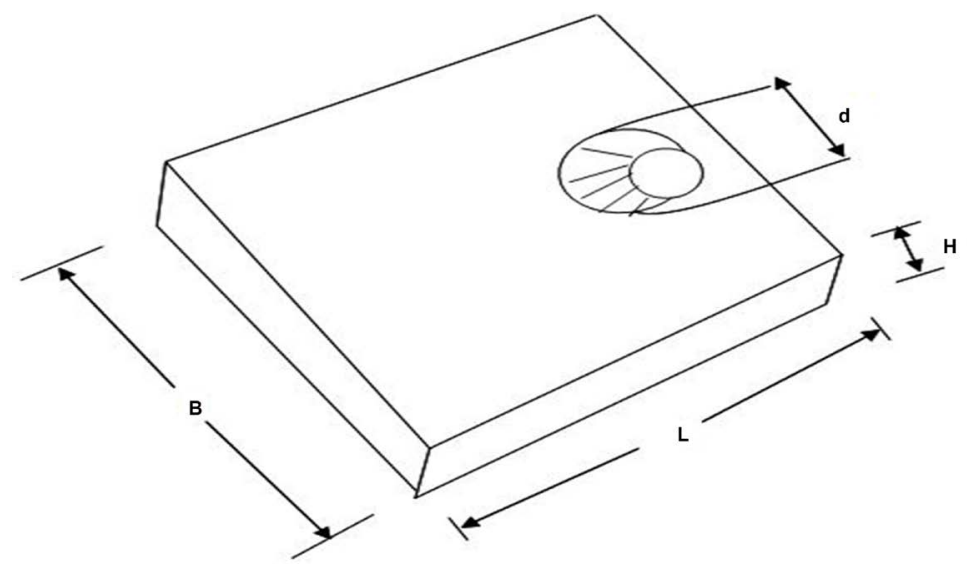

Figure 2. Specimen used for the experimentations.

$$
A=2(L B+B H+L H)+\left(\pi d H-\frac{\pi d^{2}}{2}\right)[16]
$$

where; $L=$ length of the specimen $=35 \mathrm{~mm}, H=$ thickness of the specimen $=1$ $\mathrm{mm}, d=$ bore diameter $=2.5 \mathrm{~mm}$ and $B=$ breadth of the specimen $=30 \mathrm{~mm}, \pi=$ $22 / 7, A=2228.04 \mathrm{~mm}=22.28 \mathrm{~cm}, A=$ Total Surface of the specimen $=22.28 \mathrm{~cm}$ from calculation of Equation (5).

In order to obtain exact results the specimens had to be kept in a workable state and the following steps were taken to prepare each specimen:

1) All cuts and sheared edges were ground out to prevent them from becoming sites for preferential attack.

2) Finishing of the specimen surface with grit abrasive paper (sand paper).

3) Rinsing of the specimens in distilled water.

4) Degreasing of specimen in acetone and air dried.

5) Upon drying, the specimen was immediately weighed to obtain their initial weights.

\subsection{Number of Specimen and Their Labeling}

Twelve specimens were used for the test as follow: \# $6 \mathrm{Al}$; $6 \mathrm{MS}$ samples. In order to immerse the samples into each solution, holes were made at the top sides of the plastic containers and a wooden stick placed across it. The thread was tied through the hole in each samples and placed to the wooden sticks which were marked with their corresponding label and dipped into the corrosive medium. The specimens were tagged using an $\mathrm{xxx}$ code. e.g. $1 \mathrm{~A} 1$

First character represents the percentage of inhibitor in the corrosive media immersed in $(1 \%-5 \%, 2 \%-10 \%, 3 \%-15 \%, 4 \%-20 \%, 5 \%-25 \%$ and $6 \%-0 \%)$.

Second character represents the type of the specimens (A-Aluminum S-Steel).

Third character indicates the number weeks the sample has been exposed to the corrosive media.

To prepare the inhibitor, $1200 \mathrm{~g}$ of bitter leaf was plucked, weighed and crushed. $600 \mathrm{cl}$ of water was added to the crushed leaves. The mixture was put in 
a filter cloth and squeezed with hand to filter out the active concentration ingredients responsible for corrosion inhibition. This produced a $2 M$ concentration of VA extract solution.

MS and Al samples were immersed in different plastic containers containing $400 \mathrm{ml}$ of seawater with $\mathrm{pH}$ value of 7.25 with no $(0 \%)$ inhibitor added to it; this was called the control solution. From the $2 \mathrm{M}$ bitter leaves extract solution prepared, $5 \%(400 \mathrm{ml})$ was measured using a measuring cylinder, then the corrosive medium seawater is poured into the measuring cylinder containing the $5 \%$ bitter leaves extract solution until the meniscus of the mixture reached the $400 \mathrm{ml}$ mark and the solution was put into a plastic container. The same 5\% solution was done for two different plastic containers meant for each sample-Al, and MS. Each set of the specimen were looped about the wooden sticks by the aid of the rubber strings. The specimen were suspended by the strings and completely immersed in the different percentage test media. The same procedure was carried out for each of the different percentages, $10 \%, 15 \%, 20 \%$, and $25 \%$ and a total of 12 solutions were set up.

The experimental procedure use was that seawater of $7.25 \mathrm{pH}$ was obtained from Abonnema water front of Rivers State. At the end of every week (168 hours) the following steps were taken to obtain readings:

1) Removal of specimen from corrosive media, Observation and recording of appearance of the specimen noting sites and locations of deposits and variation in types of deposits.

2) Cleaning of specimen with white handkerchief or tissue paper.

3) Washing of specimen with distilled water.

4) Scrubbing of specimen with a soft brush.

5) Dipping the specimen into acetone after washing.

6) Removing to air-dry and weighed.

Later the specimen was weighed immediately after cleaning; this is recorded as the initial weight. For each of the 12 set ups, the weight loss for each week was obtained by calculating the difference between the initial weight of each specimen and weight after immersion as shown in Equation (6).

WL $\Delta W=$ (weight at time, $t=0)-($ weight at time, $t-i)$ where $i=1-5$ weeks.

\subsection{Determination of CR}

The method used to calculate the corrosion rate is as follows; Mass loss has been used due to general corrosion and material has not been internally attacked.

The $\mathrm{CR}$ in $\mathrm{mm} / \mathrm{yr}$ is given by the relation in Equation (7)

$$
C_{R}=\frac{K \times W}{A \times T \times D} \quad[26]
$$

where, $W=$ mass loss (g), $K=C_{R}$ constant $=8.76 \times 10^{4}, A=$ area of specimen $\left(\mathrm{cm}^{2}\right), D_{1}=$ density of MS $\left(\mathrm{g} / \mathrm{cm}^{2}\right)=7.86 \mathrm{~g} / \mathrm{cm}^{3}, T=$ time of exposure in hours and $D_{2}=$ density of $\mathrm{Al}\left(\mathrm{g} / \mathrm{cm}^{2}\right)=2.7 \mathrm{~g} / \mathrm{cm}^{3}$. 


\section{Results and Discussion}

The results obtained from the experiment carried out in the previous section are tabulated between Tables 1-12. The WL and CR rate shown in the results are based on a number of factors.

Table 1. Data for WL and CR of Al sample with 5\% inhibitor.

\begin{tabular}{|c|c|c|c|c|c|}
\hline CODE & Time (hour) & Initial weight (g) & Final weight (g) & Change in weight (g) & $\mathrm{CR}(\mathrm{mm} / \mathrm{yr})$ \\
\hline $1 \mathrm{~A} 1$ & 168 & 2.9290 & 2.9181 & 0.0109 & 0.0944 \\
\hline $1 \mathrm{~A} 2$ & 336 & 2.9290 & 2.9107 & 0.0183 & 0.0793 \\
\hline $1 \mathrm{~A} 3$ & 504 & 2.9290 & 2.9105 & 0.0185 & 0.0534 \\
\hline $1 \mathrm{~A} 4$ & 672 & 2.9290 & 2.9107 & 0.0183 & 0.0396 \\
\hline $1 \mathrm{~A} 5$ & 840 & 2.9290 & 2.9114 & 0.0176 & 0.0305 \\
\hline
\end{tabular}

Table 2. Data for WL and CR of Al sample with $10 \%$ inhibitor.

\begin{tabular}{cccccc}
\hline CODE & Time (hour) & Initial weight (g) Final weight (g) & Weight loss $(\mathrm{g})$ & CR (mm/yr) \\
\hline 2A1 & 168 & 2.9808 & 2.98 & 0.0008 & 0.006934 \\
2A2 & 336 & 2.9808 & 2.9793 & 0.0015 & 0.006501 \\
2A3 & 504 & 2.9808 & 2.9778 & 0.003 & 0.008668 \\
2A4 & 672 & 2.9808 & 2.9761 & 0.0047 & 0.010185 \\
2A5 & 840 & 2.9808 & 2.8763 & 0.0487 & 0.084426 \\
\hline
\end{tabular}

Table 3. Data for WL and CR of Al sample with $15 \%$ inhibitor.

\begin{tabular}{cccccc}
\hline CODE & Time (hour) & Initial weight $(\mathrm{g})$ & Final weight $(\mathrm{g})$ & Weight loss $(\mathrm{g})$ & $\mathrm{CR}(\mathrm{mm} / \mathrm{yr})$ \\
\hline 3A1 & 168 & 2.6877 & 2.6871 & 0.0006 & 0.0052 \\
3A2 & 336 & 2.6877 & 2.6853 & 0.0024 & 0.0104 \\
3A3 & 504 & 2.6877 & 2.6802 & 0.0075 & 0.0216 \\
3A4 & 672 & 2.6877 & 2.6785 & 0.0092 & 0.0199 \\
3A5 & 840 & 2.6877 & 2.6719 & 0.0158 & 0.0273 \\
\hline
\end{tabular}

Table 4. Data for WL and CR of Al sample with $20 \%$ inhibitor.

\begin{tabular}{|c|c|c|c|c|c|}
\hline CODE & Time (hour) & Initial weight (g) & Final weight (g) & Change in weight (g) & $\mathrm{CR}(\mathrm{mm} / \mathrm{yr})$ \\
\hline $4 \mathrm{Al}$ & 168 & 2.7698 & 2.7685 & 0.0013 & 0.0112 \\
\hline $4 \mathrm{~A} 2$ & 336 & 2.7698 & 2.7681 & 0.0017 & 0.0074 \\
\hline $4 \mathrm{~A} 3$ & 504 & 2.7698 & 2.7680 & 0.0018 & 0.0052 \\
\hline $4 \mathrm{~A} 4$ & 672 & 2.7698 & 2.7669 & 0.0029 & 0.0063 \\
\hline $4 \mathrm{~A} 5$ & 840 & 2.7698 & 2.7645 & 0.0053 & 0.0092 \\
\hline
\end{tabular}

Table 5. Data for WL and CR of Al sample with 25\% inhibitor.

\begin{tabular}{|c|c|c|c|c|c|}
\hline CODE & Time (hour) & ) Initial weight (g) & Final weight (g) & Change in weight (g) & $\mathrm{CR}(\mathrm{mm} / \mathrm{yr})$ \\
\hline $5 \mathrm{~A} 1$ & 168 & 2.8123 & 2.7036 & 0.1087 & 0.3236 \\
\hline $5 \mathrm{~A} 2$ & 336 & 2.8123 & 2.7204 & 0.0919 & 0.1368 \\
\hline
\end{tabular}


Continued

\begin{tabular}{llllll}
\hline 5A3 & 504 & 2.8123 & 2.7175 & 0.0948 & 0.0941 \\
5A4 & 672 & 2.8123 & 2.7003 & 0.1120 & 0.0834 \\
5A5 & 840 & 2.8123 & 2.7001 & 0.1122 & 0.0668 \\
\hline
\end{tabular}

Table 6. Data for WL and CR of $\mathrm{Al}$ sample with $0 \%$ inhibitor.

\begin{tabular}{cccccc}
\hline CODE & \multicolumn{2}{c}{ Time (hour) Initial weight $(\mathrm{g})$ Final weight $(\mathrm{g})$} & Change in weight (g) & CR (mm/yr) \\
\hline 6A1 & 168 & 2.8465 & 2.7474 & 0.0991 & 0.8590 \\
6A2 & 336 & 2.8465 & 2.6775 & 0.1690 & 0.7324 \\
6A3 & 504 & 2.8465 & 2.6353 & 0.2112 & 0.6102 \\
6A4 & 672 & 2.8465 & 2.6310 & 0.2455 & 0.5319 \\
6A5 & 840 & 2.8465 & 2.5903 & 0.2562 & 0.4441 \\
\hline
\end{tabular}

Table 7. Data for WL and CR of MS samples with 5\% inhibitor.

\begin{tabular}{cccccc}
\hline CODE & Time (hour) & Initial weight $(\mathrm{g})$ Final weight $(\mathrm{g})$ Change in weight $(\mathrm{g})$ & CR (mm/yr) \\
\hline 1S1 & 168 & 6.6576 & 6.6321 & 0.0255 & 0.0759 \\
1S2 & 336 & 6.6576 & 6.6239 & 0.0337 & $0.050 \mathrm{I}$ \\
1S3 & 504 & 6.6576 & 6.6149 & 0.0427 & 0.0423 \\
1S4 & 672 & 6.6576 & 6.6127 & 0.0449 & 0.0334 \\
1S5 & 840 & 6.6576 & 6.6103 & 0.0473 & 0.0281 \\
\hline
\end{tabular}

Table 8. Data for WL and CR of MS samples with $10 \%$ inhibitor.

\begin{tabular}{cccccc}
\hline CODE & Time (hour) & Initial weight (g) & Final weight (g) & Change in weight (g) & CR (mm/yr) \\
\hline 2S1 & 168 & 6.2922 & 6.2519 & 0.0403 & 0.1199 \\
$2 \mathrm{~S} 2$ & 336 & 6.2922 & 6.2487 & 0.0435 & 0.0647 \\
$2 \mathrm{~S} 3$ & 504 & 6.2922 & 6.2453 & 0.0469 & 0.0465 \\
$2 \mathrm{~S} 4$ & 672 & 6.2922 & 6.2451 & 0.0471 & 0.0350 \\
$2 \mathrm{~S} 5$ & 840 & 6.2922 & 6.2219 & 0.0703 & 0.0418 \\
\hline
\end{tabular}

Table 9. Data for WL and CR of MS samples with 15\% inhibitor.

\begin{tabular}{cccccc}
\hline CODE & Time (hour) Initial weight (g) Final weight (g) & Change in weight (g) & CR (mm/yr) \\
\hline 3S1 & 168 & 6.7667 & 6.766 & 0.0007 & 0.0021 \\
3S2 & 336 & 6.7667 & 6.752 & 0.0147 & 0.0218 \\
3S3 & 504 & 6.7667 & 6.7511 & 0.0156 & 0.0154 \\
3S4 & 672 & 6.7667 & 6.7507 & 0.016 & 0.0119 \\
3S5 & 840 & 6.7667 & 6.7501 & 0.0166 & 0.0098 \\
\hline
\end{tabular}

Table 10. Data for WL and CR of MS samples with $20 \%$ inhibitor.

\begin{tabular}{cccccc}
\hline CODE & Time (hour) & Initial weight $(\mathrm{g})$ Final weight $(\mathrm{g})$ & Change in weight $(\mathrm{g})$ & $\mathrm{CR}(\mathrm{mm} / \mathrm{yr})$ \\
\hline 4S1 & 168 & 6.6391 & 6.6372 & 0.0019 & 0.0056 \\
4S2 & 336 & 6.6391 & 6.6344 & 0.0047 & 0.0069 \\
4S3 & 504 & 6.6391 & 6.6120 & 0.0271 & 0.0268 \\
4S4 & 672 & 6.6391 & 6.6090 & 0.0301 & 0.0224 \\
4S5 & 840 & 6.6391 & 6.5890 & 0.0501 & 0.0298 \\
\hline
\end{tabular}


Table 11. Data for WL and CR of MS samples with 25\% inhibitor.

\begin{tabular}{cccccc}
\hline CODE & \multicolumn{2}{c}{ Time (hour) Initial weight (g) Final weight (g) } & Change in weight (g) & CR (mm/yr) \\
\hline $5 S 1$ & 168 & 6.5976 & 6.5963 & 0.0013 & 0.0038 \\
$5 S 2$ & 336 & 6.5976 & 6.5925 & 0.0051 & 0.0075 \\
$5 \mathrm{~S} 3$ & 504 & 6.5976 & 6.5917 & 0.0059 & 0.0058 \\
$5 \mathrm{~S} 4$ & 672 & 6.5976 & 6.5900 & 0.0076 & 0.0056 \\
$\mathbf{5 S 5}$ & 840 & 6.5976 & 6.5890 & 0.0086 & 0.0051 \\
\hline
\end{tabular}

Table 12. Data for WL and CR of MS samples with $0 \%$ inhibitor.

\begin{tabular}{|c|c|c|c|c|c|}
\hline CODE & Time hour & Initial weight $(\mathrm{g})$ & Final weight (g) & Change in weight $(\mathrm{g})$ & $\mathrm{CR}(\mathrm{mm} / \mathrm{yr})$ \\
\hline $6 \mathrm{~S} 1$ & 168 & 6.8217 & 6.6139 & 0.2078 & 0.6187 \\
\hline $6 S 2$ & 336 & 6.8217 & 6.6120 & 0.2097 & 0.3122 \\
\hline $6 \mathrm{~S} 3$ & 504 & 6.8217 & 6.5345 & 0.2872 & 0.2872 \\
\hline $6 S 4$ & 672 & 6.8217 & 6.5310 & 0.2907 & 0.2164 \\
\hline $6 \mathrm{~S} 5$ & 840 & 6.8217 & 6.5117 & 0.3100 & 0.1846 \\
\hline
\end{tabular}

The values of the above tables are plotted in a graph of WL against time and CR against time as shown in Figures 3-26. This is to aid easy comparison of the rate of corrosion of each sample in the different percentages of inhibiting solution.

Figure 3, Figure 4, Figure 15 and Figure 16 represent the graph of $\mathrm{CR}$ against time and WL against time for $\mathrm{Al}$ and MS samples with 5\% inhibitor respectively. It can seen that at the first week of exposure to corrosive medium there was a substantial reduction in weight of coupons but over the next three weeks there was a gradual decline in weight loss and the corrosion rate reduced evenly .although the medium is inhibited there is still a good percentage of corrosion of coupons It can be said that the percentage of inhibitor to corrosive medium (sea water) is insufficient. Figures 5-8 and Figures 7-10 represent the graph of $\mathrm{CR}$ against time and WL against time for $\mathrm{Al}$ and $\mathrm{MS}$ samples with $10 \%$ and $15 \%$ inhibitor respectively. This shows that there is an effective control of corrosion in the coupons over the period of the experiment. It represent an optimal inhibiting process to a great extent. Figures 15-18 and Figures 17-20 represent the graph of $\mathrm{CR}$ against time and WL against time for $\mathrm{Al}$ and MS samples with $20 \%$ and $25 \%$ inhibitor respectively. It is observed that after the first 3 weeks of testing there is a great decrease in CR. This explains that even with increasing percentage of inhibitor the $\mathrm{CR}$ is not reduced correspondingly. So a right percentage of inhibitor needs to be administered. Figure 13, Figure 14, Figure 25 and Figure 26 represent the graph of CR against time and WL against time for $\mathrm{Al}$ and MS samples with $0 \%$ inhibitor respectively. This is the control solution; the coupons are vulnerable to corrosion. WL determination has a number of attractive features that account for its sustained popularity, some of the advantages are as follow; it is simple because no sophisticated instrumentation 


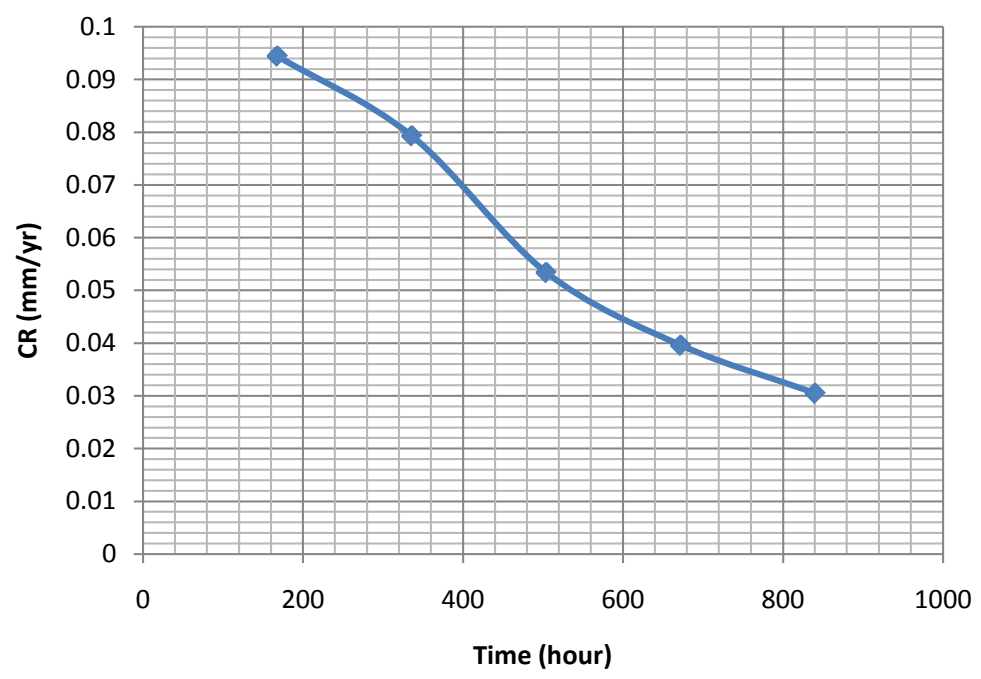

Figure 3. CR against time for AL for samples with $5 \%$ inhibitor.

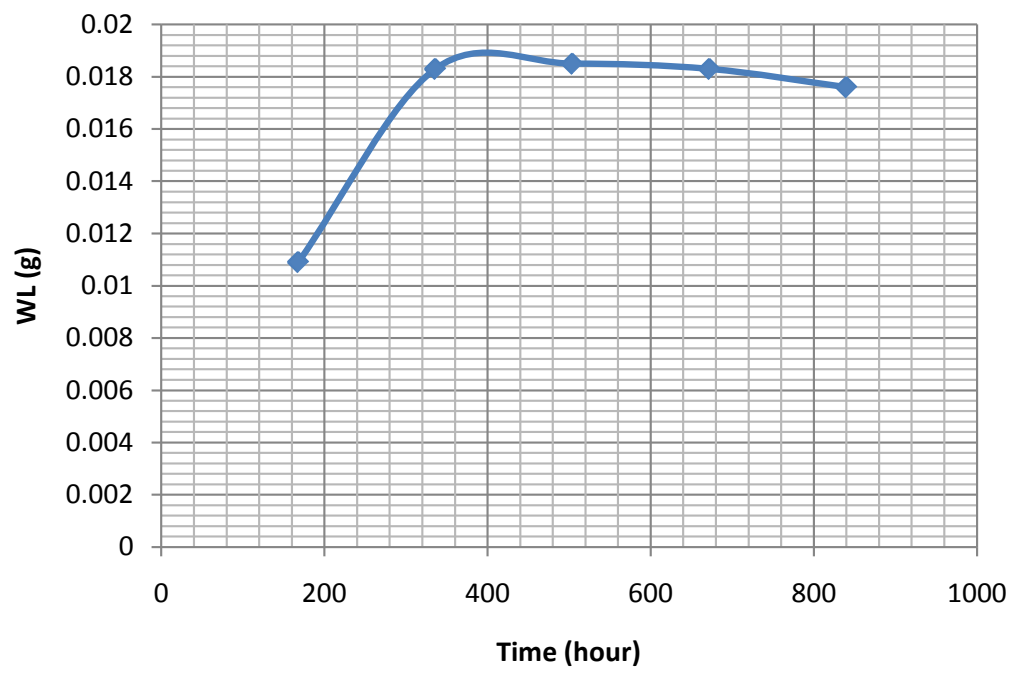

Figure 4. WL against time for AL for samples with 5\% inhibitor.

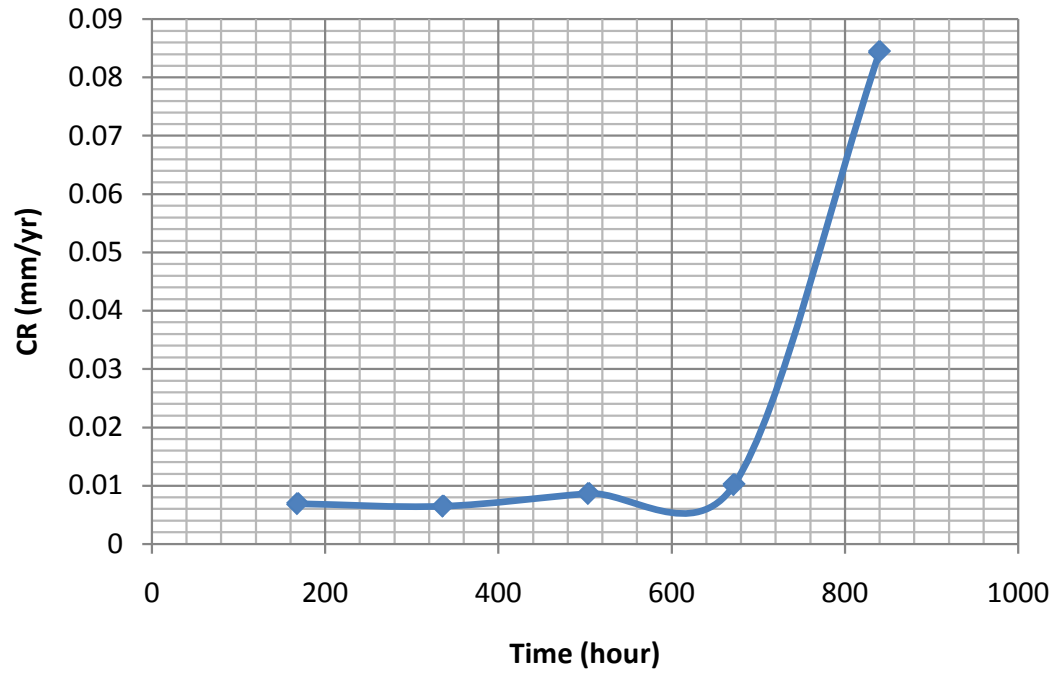

Figure 5. CR against time for AL for samples with $10 \%$ inhibitor. 


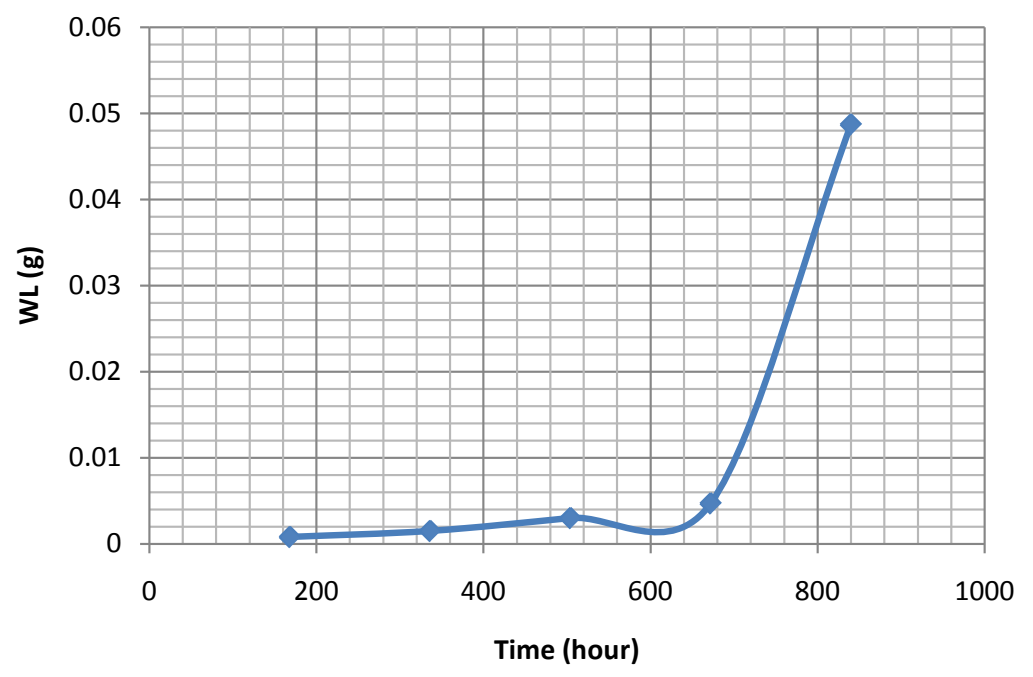

Figure 6. WL against time for AL for samples with $10 \%$ inhibitor.

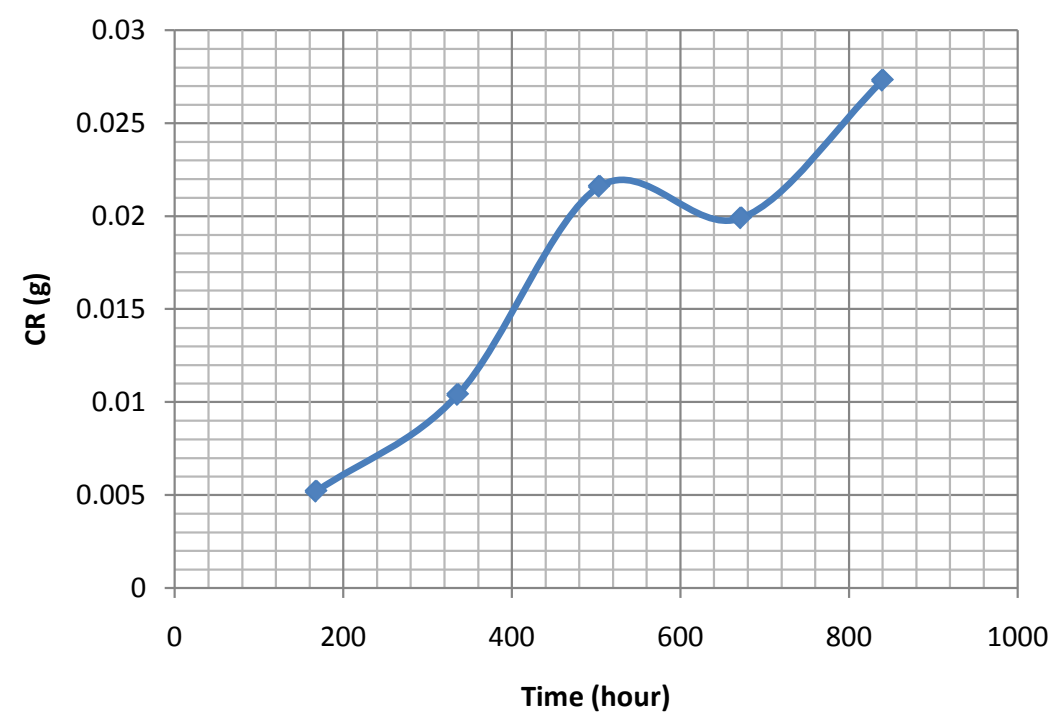

Figure 7. CR against time for AL for samples with $15 \%$ inhibitor.

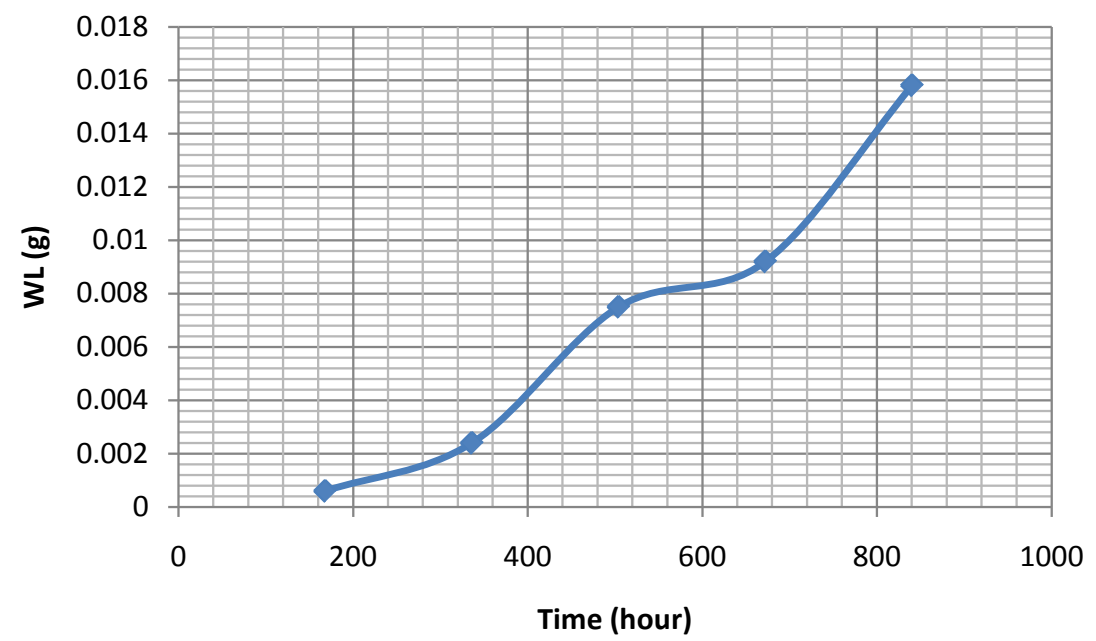

Figure 8. WL against time for AL for samples with 15\% inhibitor. 


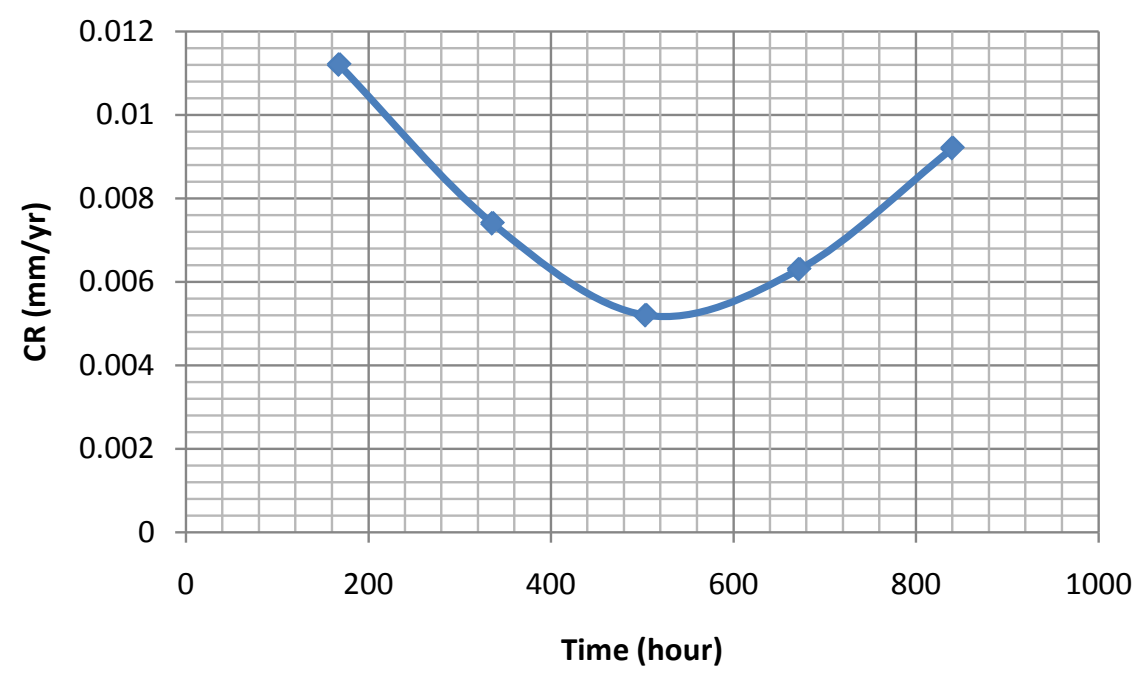

Figure 9. CR against time for AL for samples with $20 \%$ inhibitor.

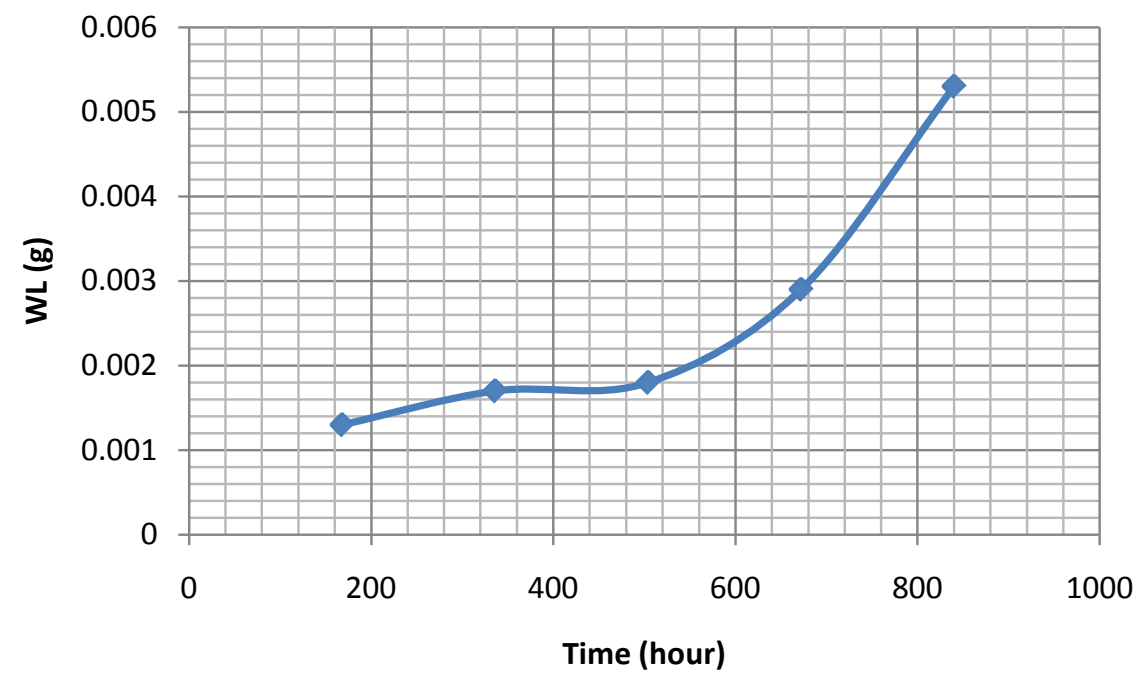

Figure 10. WL against time for AL for samples with $20 \%$ inhibitor.

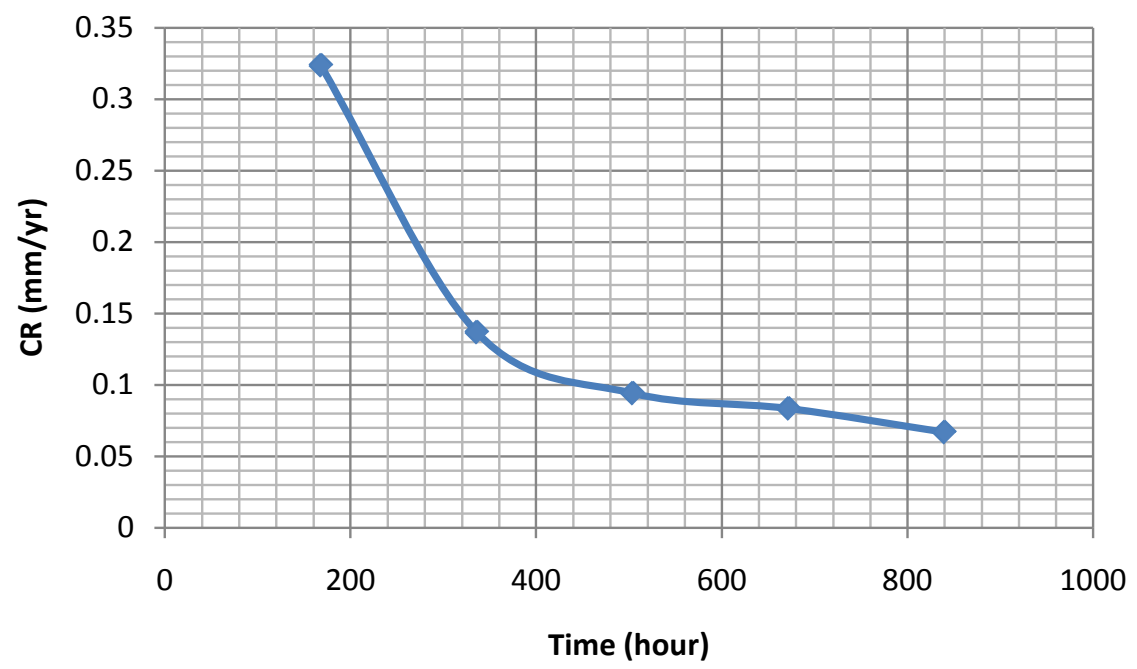

Figure 11. CR against time for AL for samples with $25 \%$ inhibitor. 


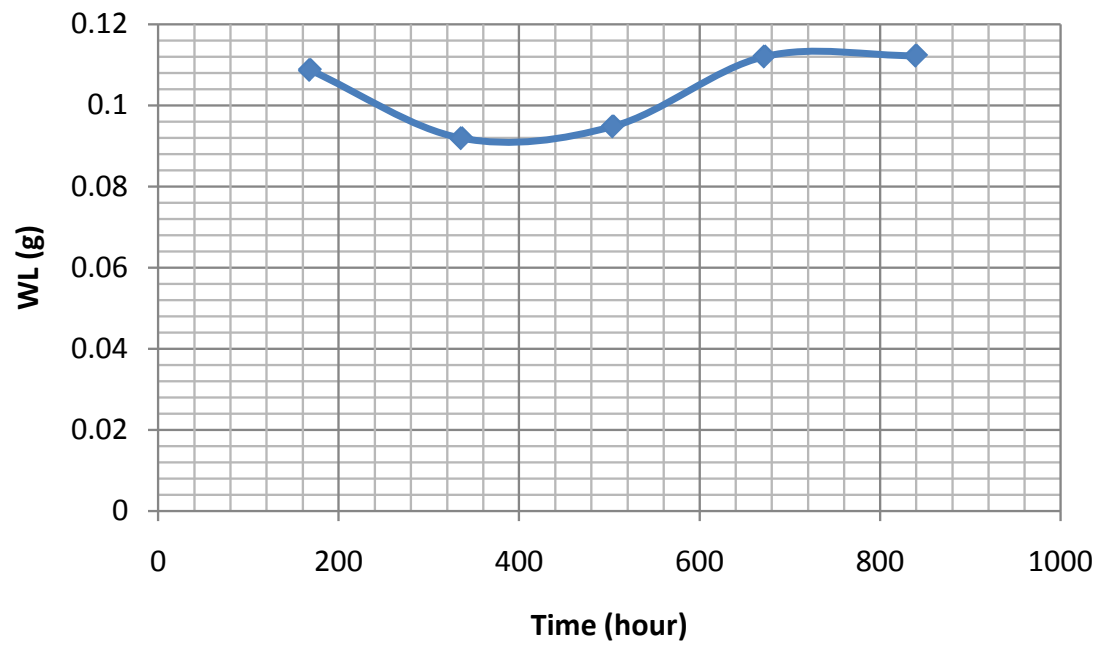

Figure 12. WL against time for AL for samples with 25\% inhibitor.

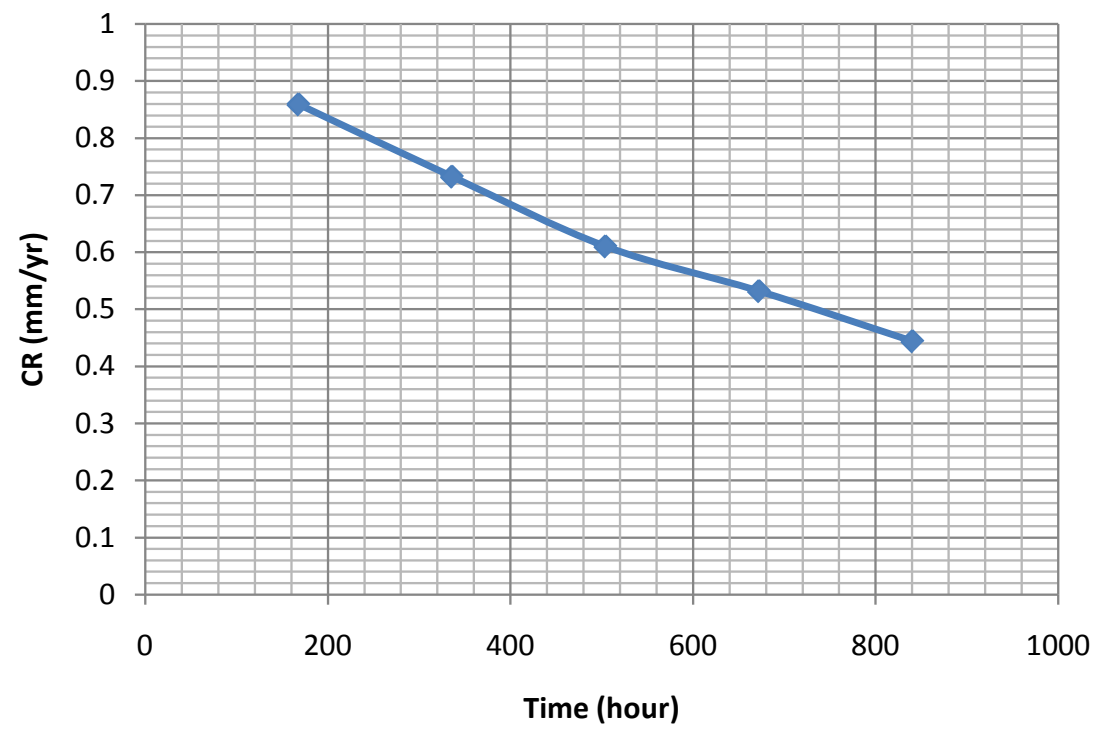

Figure 13. CR against time for AL for samples with $0 \%$ inhibitor.

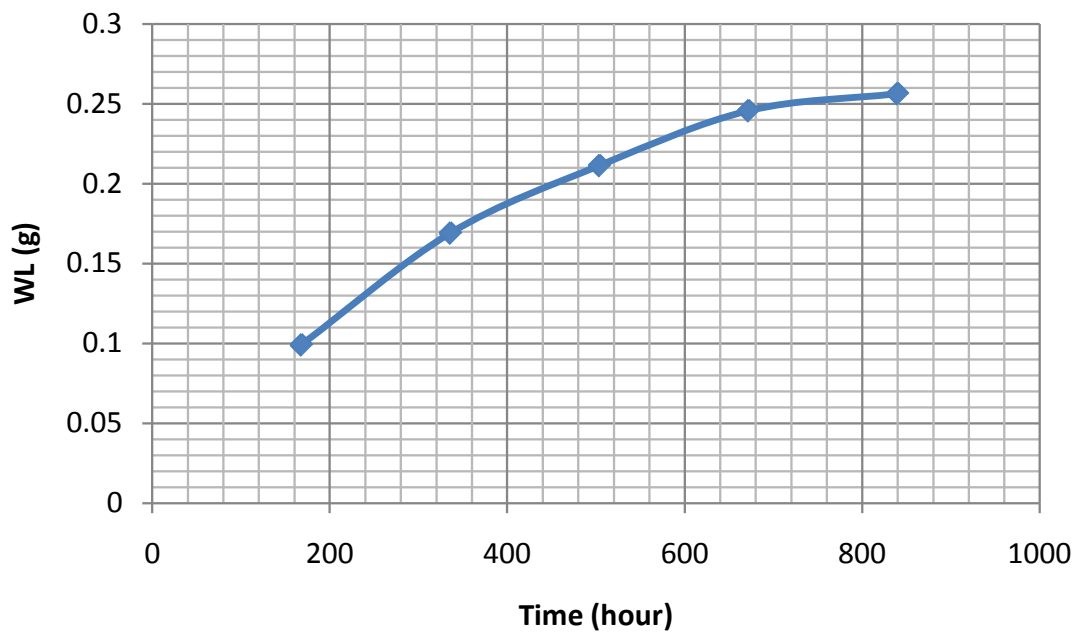

Figure 14. WL against time for AL for samples with $0 \%$ inhibitor. 


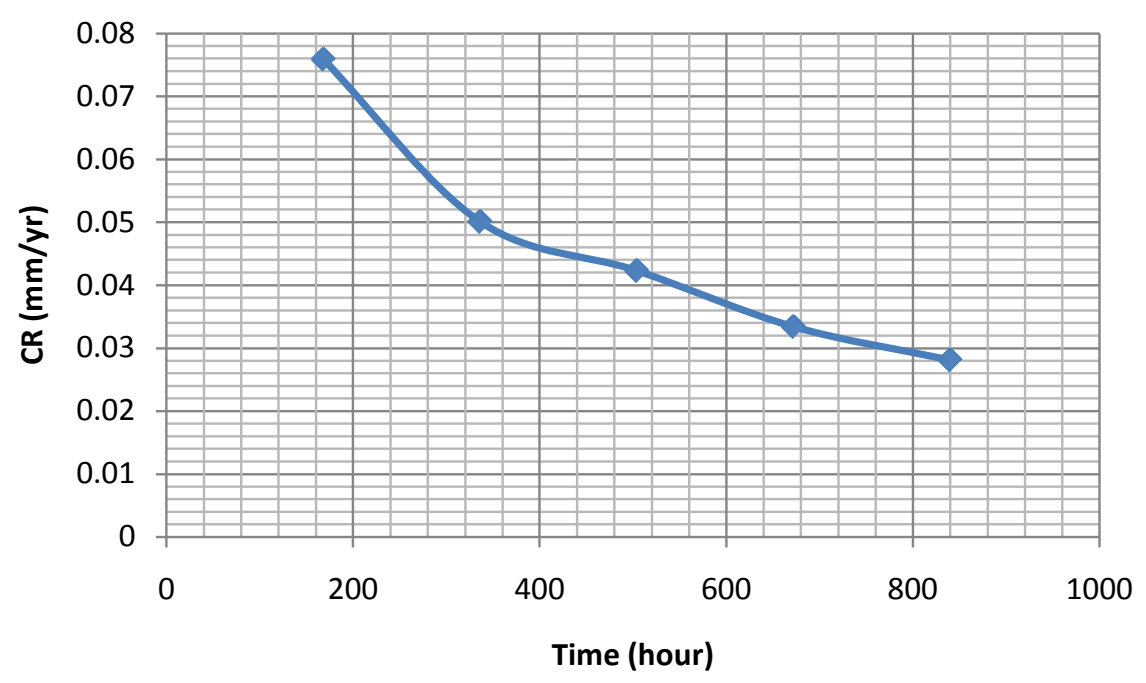

Figure 15. CR against time for MS for samples with 5\% inhibitor.

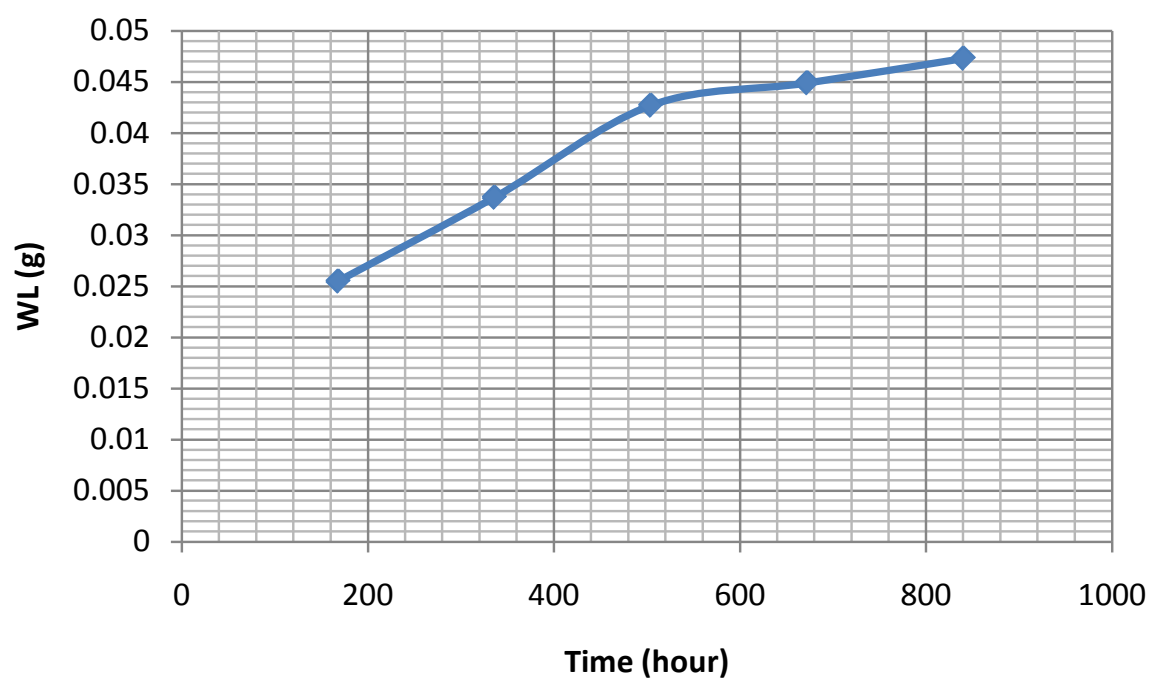

Figure 16. WL against time for MS for samples with 5\% inhibitor.

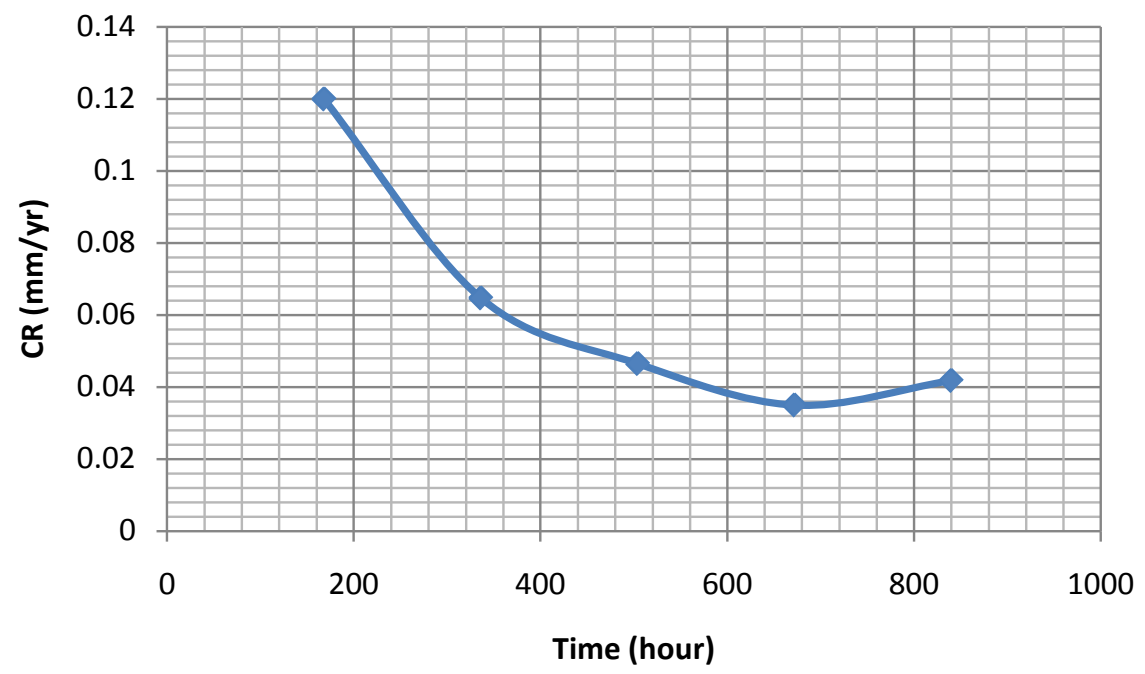

Figure 17. CR against time for MS for samples with 10\% inhibitor. 


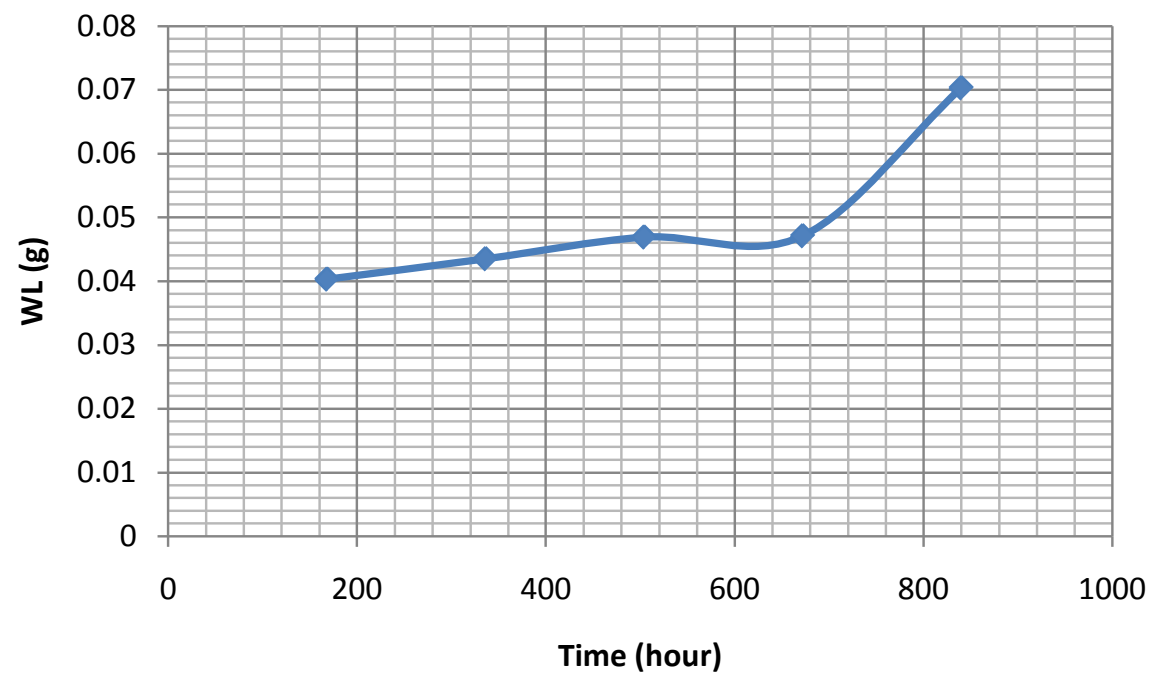

Figure 18. WL against time for MS for samples with $10 \%$ inhibitor.

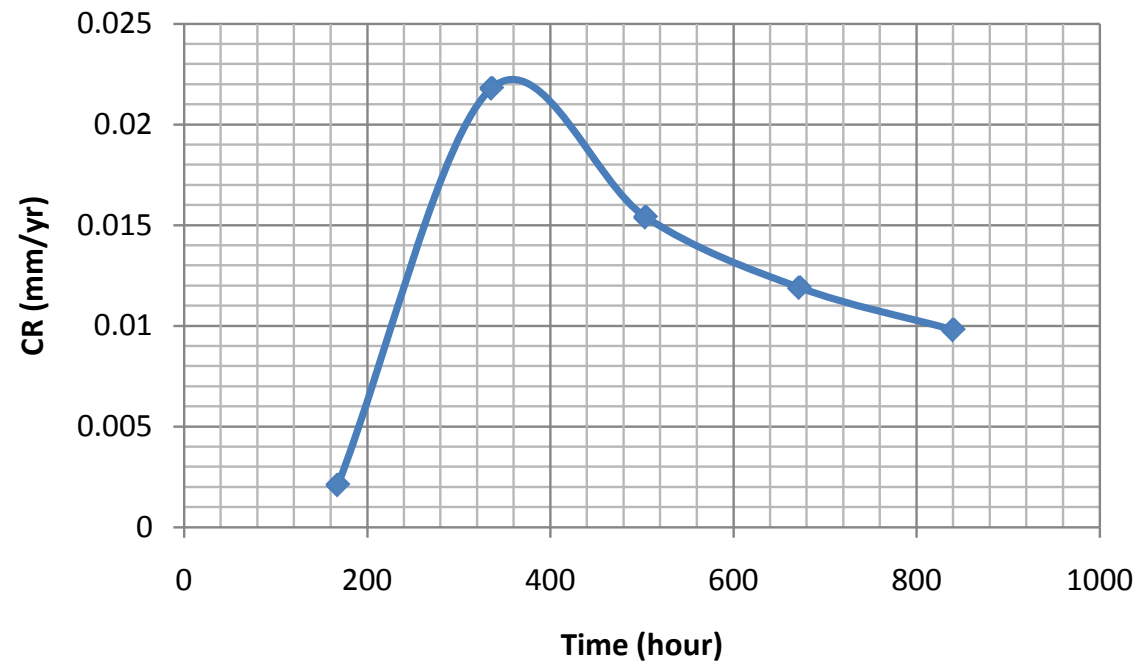

Figure 19. CR against time for MS for samples with 15\% inhibitor.

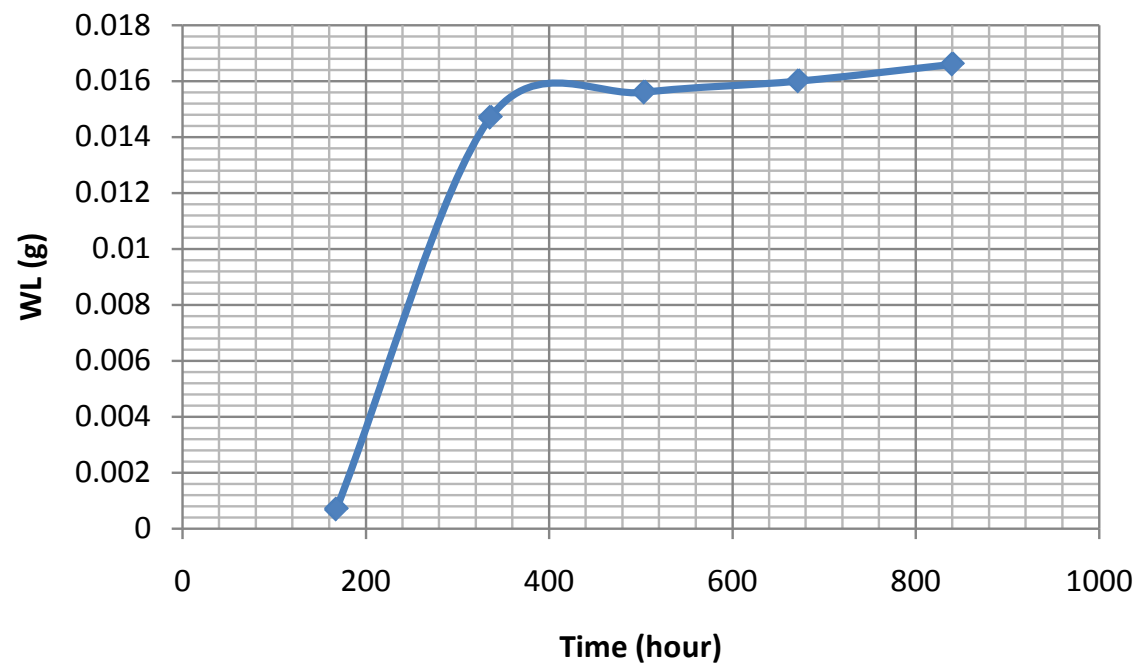

Figure 20. WL against time for MS for samples with 15\% inhibitor. 


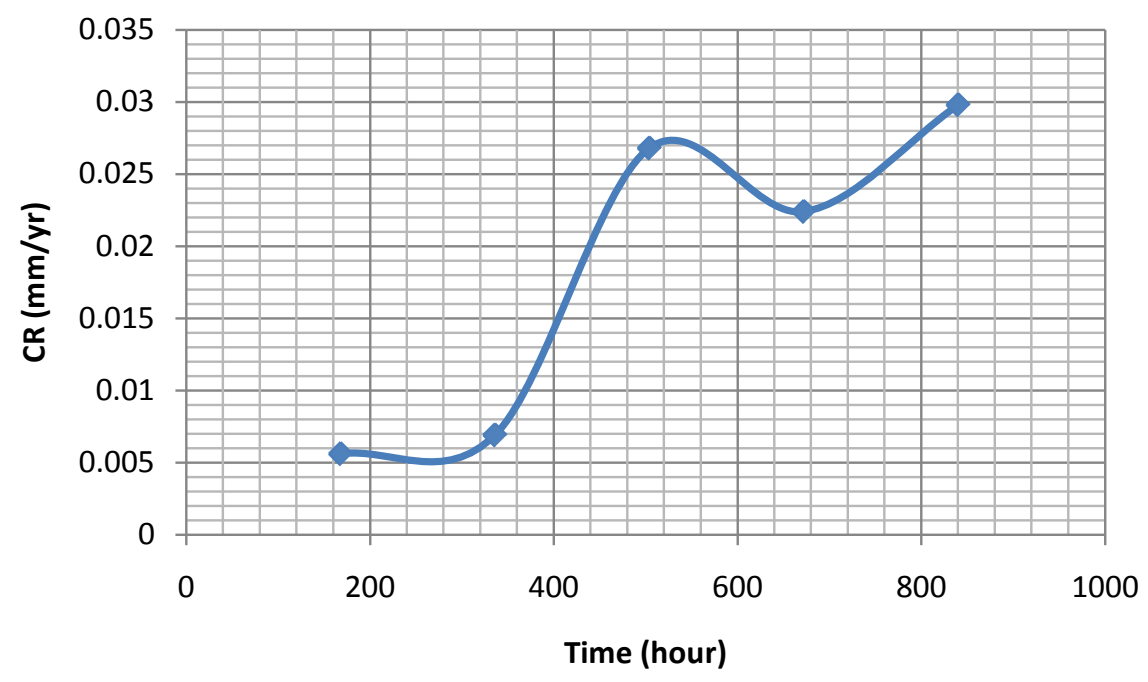

Figure 21. CR against time for MS for samples with 20\% inhibitor.

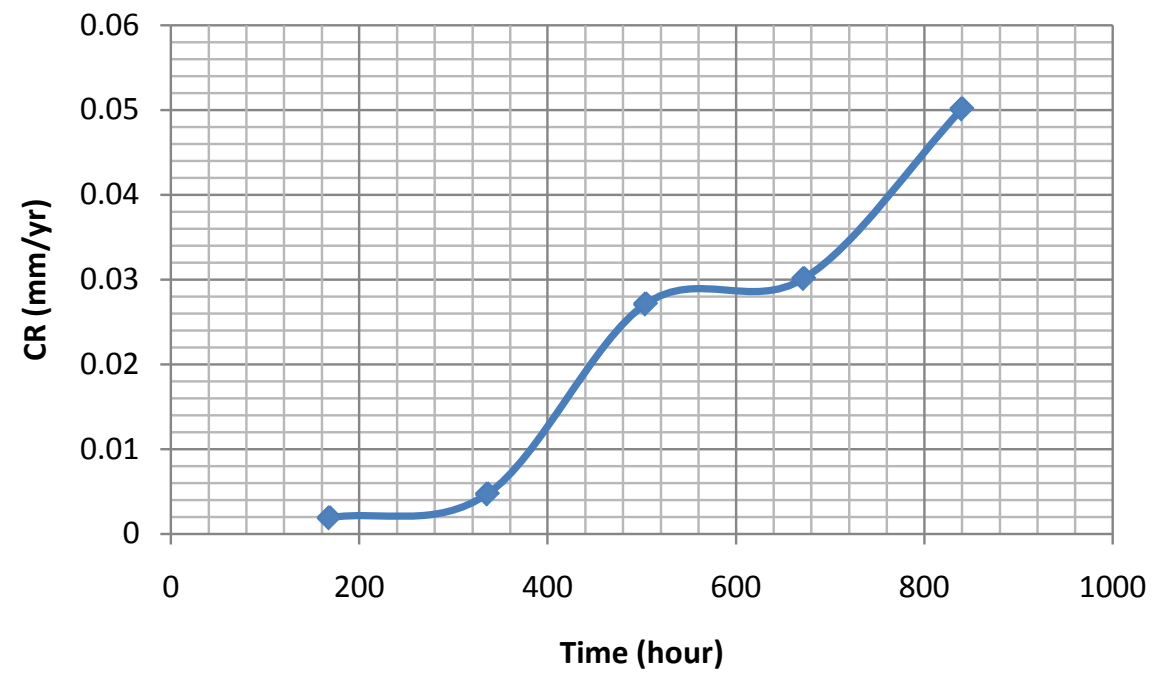

Figure 22. WL against time for MS for samples with $20 \%$ inhibitor.

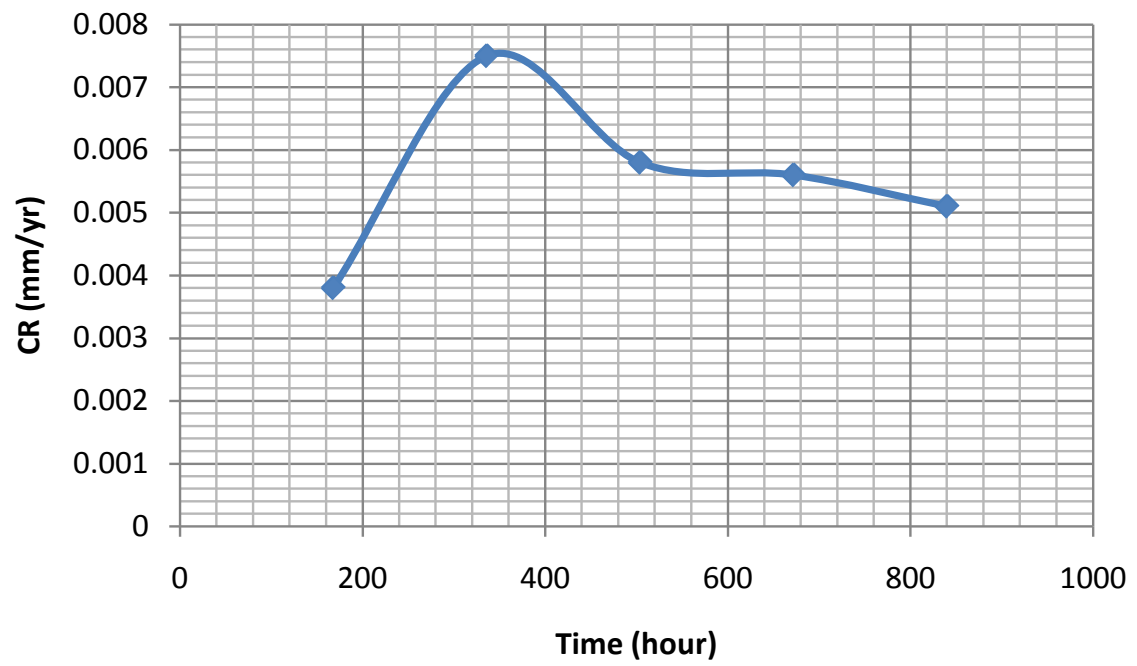

Figure 23. CR against time for MS for samples with 25\% inhibitor. 


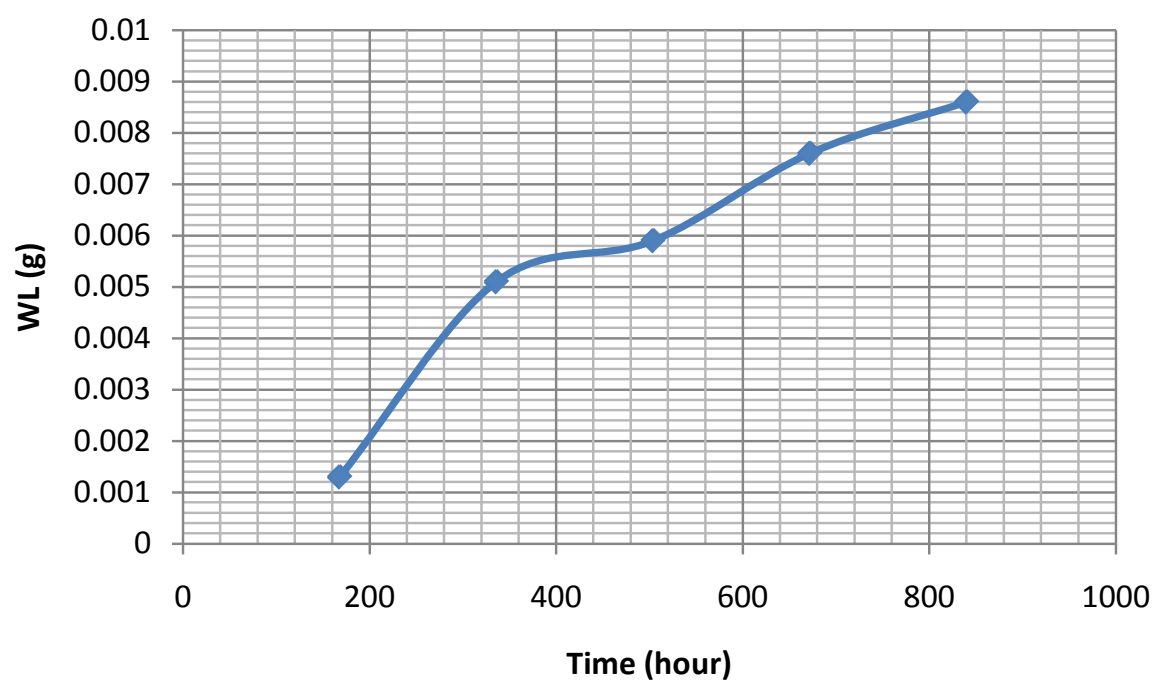

Figure 24. WL against time for MS for samples with 25\% inhibitor.

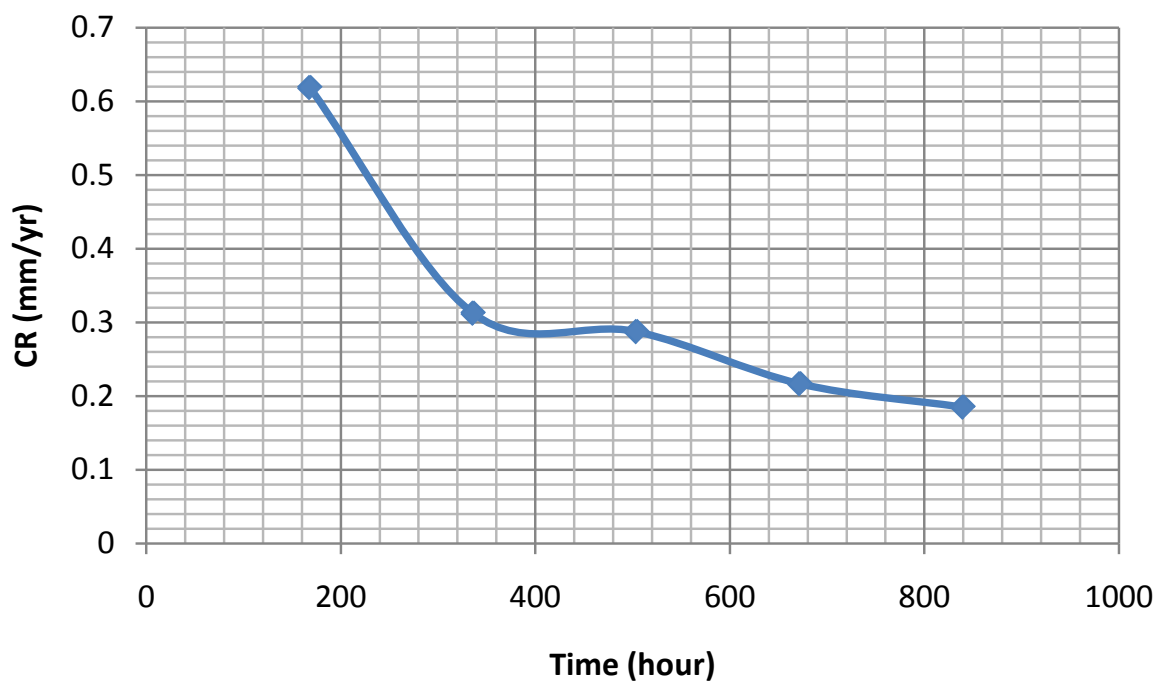

Figure 25. CR against time for MS for samples with $0 \%$ inhibitor.

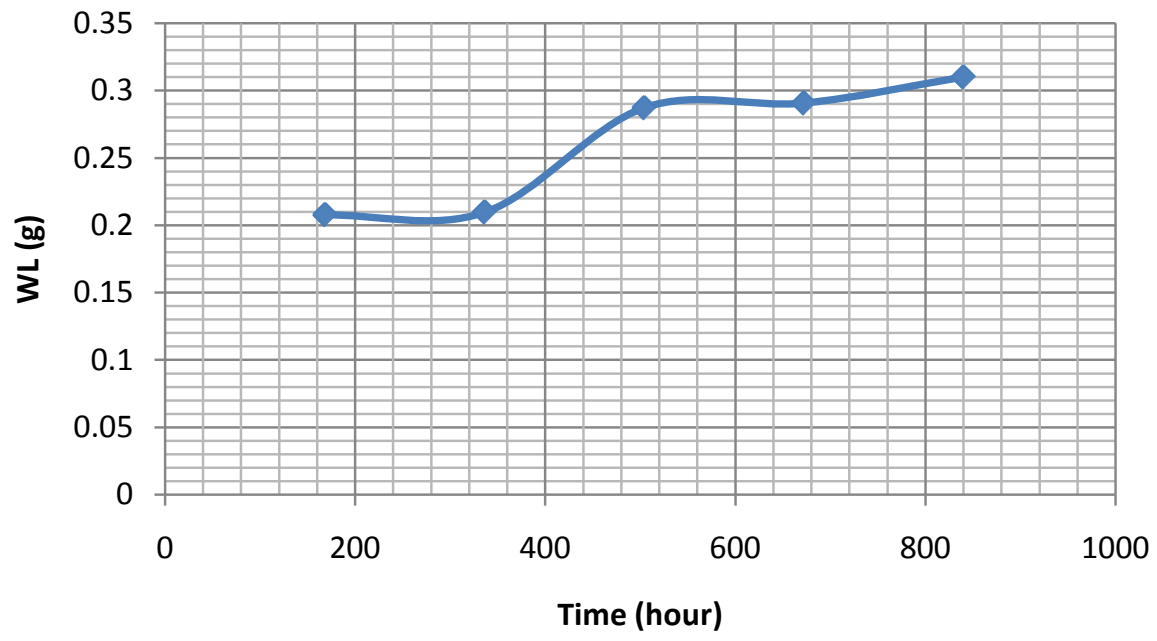

Figure 26. WL against time for MS for samples with $0 \%$ inhibitor. 
is required to obtain a result, it is direct because a direct measurement is obtained, with no theoretical assumption or approximations, it is also versatile because it is applicable to all corrosive environments, and gives information on all forms of corrosion and it is visual because inspection can be undertaken. Furthermore corrosion deposits can be observed and analyzed, weight loss can be readily determined and rate easily calculated, localized corrosion can be identified and measured and inhibitor performance can be easily assessed.

\section{Conclusion}

The inhibitor $V A$ introduced into the corrosive medium reacts in such a way as to neutralize the chloride present in the medium by the chemical reaction of its metals to form sparingly soluble salts; this action retards the corrosion process of the coupons and this can be adopted in combating corrosion in steel and $\mathrm{Al}$ pipes for industrial use. The research work of combating corrosion in pipelines in seawater using $V A$ inhibitors shows that optimum inhibition of coupons was obtained between $15 \%$ - 25\% of 2 M Concentration of the inhibitor and during the first four weeks of testing. At the fifth week, the inhibitor was gradually losing its effectiveness. This means that more inhibitor need be added at regular intervals to sustain the effectiveness of the inhibitor. It is also of vital interest to apply the right concentration of inhibitor since CR increases at high concentrations and temperature. The graphs of $\mathrm{Al}$ when compared to that of MS exhibited a good degree of tolerance in the inhibited solution. From this research work, we can say that proper corrosion control programme should be adapted before pipelines installations. Monitoring techniques should also be continued during its useful lifespan. This is essential because this organic inhibitor loses its properties and reduces its effectiveness over time. It is also important that means of using this inhibitor on corrosive medium at high temperatures and velocities should be introduced since this research was carried out at room temperature and zero flow rate conditions. Although this inhibitor is cheap and easily available, they may possess disparities in their chemical composition since they are of various species. So their concentrations and inhibiting properties may differ, hence for industrial applications, more studies on these properties should be carried out. The results of this work could be of immense value to the $O \& G$ industries.

\section{Conflicts of Interest}

The authors declare no conflicts of interest regarding the publication of this paper.

\section{References}

[1] Aced Students Portal (2014) Wikipedia. Copyright@2005.

[2] Inegiyemiema, M. and Nitonye, S. (2015). Hydrodynamic Analysis of a Column Structure of a Petroleum Storage Tank. International Journal of Scientific and Engineering Research, 5, 739-752. http://www.ijser.org 
[3] Okoroafor, C. (2004) Cathodic Protection as a Means of Saving National Asset. Journal of Corrosion Science and Technology, 1, 1-6.

[4] Alawode, A.J. and Ogunleye, I.O. (2011) Maintenance, Security and Environmental Implications of Pipeline Damage and Ruptures in the Niger Delta Region. Pacific Journal of Science and Technology, 12, 565-573.

[5] Beavers, J. (2007) Semantic Prominence in the Syntax: A Case Study in English Object/Oblique Alternations. The University of Kentucky at Lexington, KY.

[6] Fontana, M.G. (1986) Corrosion Engineering. Mc Graw-Hill, Inc., New York, New York.

[7] Encyclopedia of Electrochemistry Website (2001) http://electrochem.cwru.edu/ed/encycl/

[8] Natarajan, K.A. and Fortana, M.G. (2006) Advances in Corrosion Engineering, Ilsc Bangalore. Corrosion Engineering. Mc Graw-Hill, Inc., New York.

[9] Fontana, M.G. and Greene, N.D. (2010) Corrosion Engineering, Materials Science and Engineering, University of Minnesota. McGraw-Hill, Inc., New York, 1978.

[10] Beavers, A.J., Peabody, A.W. and Little, B.J. (2007) Control of Pipeline Corrosion. NACE International, Houston Tex.

[11] Samson, N. (2015) Stress and Resistance Analysis for the Design of a Work Barge. International Journal of Scientific and Engineering Research, 6, pn-1064974. http://www.ijser.org

[12] Iduk, U. and Samson, N. (2015) Effects and Solutions of Marine Pollution from Ships in Nigerian Waterways. International Journal of Scientific and Engineering Research, 6, 782-792. http://www.ijser.org

[13] Ekine, A.S. and Emujakporue, G.O. (2010) Investigation of Corrosion of Buried Oil Pipeline by the Electrical Geophysical Methods. Journal of Applied Science and Environmental Management, 14, 63-65. https://doi.org/10.4314/jasem.v14i1.56492

[14] Ilman, M.N. Analysis of Internal Corrosion in Subsea Oil Pipelines. Gadjah Mada University, Yogyakarta.

[15] Inegiyemiema, M., Nitonye, S., Dick, I.F. and Erekosima, A. (2014) Design of a Mooring System for an Offshore Structure (A Case Study of 5000-Tonnes Offshore Work Barge [WB]). International Journal of Engineering and Technology, 4, 683-692. http://www.ijet.journal.org

[16] Raouf, A.A. and Ahmed, M.F. (2011) The General Equation of the Pipe to Soil Potential at All Humidity Conditions by the Use of both Soil Factor and Stray Potential of the Pipe-Soilearthing Grid System. Journal of American Science, 7, 787-795.

[17] Ogbonna, I.J. (2008) Mechanism and Modeling of Atmospheric Corrosion of ZincCoated Iron Sheets along the South-Eastern Coast of the Niger Delta. Ph.D Thesis, University of Calabar, Calabar.

[18] Osakuni, M.U. and Abam, T.K. (2004) Shallow Resistivity Measurement for Cathodic Protection of Pipelines in the Niger Delta. Journal of Environmental Geology, 45, 747-752. https://doi.org/10.1007/s00254-003-0916-9

[19] Samson, N. and Ogbonnaya, E.A. (2015) Optimized Condition Monitoring Model for Performance Evaluation of a Shell and Tube Heat Exchanger. International Research Journal in Engineering, Science and Technology (IREJEST), 12, 21-34. http://www.irejest.org

[20] Corrosion Doctors Website (2001). http://www.corrosion-doctors.org

[21] Andrew, E.R., Graham, E.C.B., Sleven, J.D., Foreman, S., American Water Works 
Association Research Foundation (2005) External Corrosion and Corrosion Control of Buried Water Mains. American Water Works Association, 159 p.

[22] Tuaweri, T.J., Ogbonnaya, E.A. and Onyemaobi, O.O. (2015) Corrosion Inhibition of Heat Treated Mild Steel with Neem Leaves Extract in a Chloride Medium. International Journal of Research in Engineering and Technology, 4, 404-409.

https://www.ijret.org

https://doi.org/10.15623/ijret.2015.0406069

[23] Sully, J.R and Taylor D.W. (2004) Electrochemical Methods of Corrosion Testing Metals Handbook. Vol. 13.

[24] Tuaweri, T.J. and Ogbonnaya, E.A. (2017) Corrosion Inhibition Characteristics of Vernonia Amygdalina (Bitter Leaf) on Mild Steel in Seawater. Journal of Science and Engineering Research, 4, 6-13. http://www.jsaer.com/

[25] Standard Practice 2007. Protective Criteria. National Association of Corrosion Engineers International, Sp0169.

[26] Ahmed, I., Islam, A. and Ali, N. (2017) Determination of Corrosion Rate of Mild Steel in different Medium Measuring Current Density. International Conference on Mechanical Engineering and Renewable Energy, Chittagong, Bangladesh, 18-20 December 2017, 1-4.

https://www.researchgate.net/publication/321998150_DETERMINATION_OF_CO RROSION_RATE_OF_MILD_STEEL_IN_DIFFERENT_MEDIUM_MEASURING _CURRENT_DENSITY 